\section{Cistitis enfisematosa}

\section{Sr. Director:}

La cistitis enfisematosa es una entidad rara que se caracteriza por la presencia de gas tanto en el interior de la vejiga como en la pared o en ambas, producida por la presencia de bacilos aerobios gram negativos principalmente, formadores de gas. Los factores de riesgo que predisponen a esta patología son la diabetes mellitus, el sexo femenino, infección urinaria de repetición, obstrucciones del tracto urinario, vejiga neurógena y estados de inmunosupresión. Presentamos un caso de cistitis enfisematosa, en un paciente varón que no es diabético. Dado que los factores predisponentes que con mayor frecuencia se asocian a esta entidad son la diabetes mellitus y sexo femenino, y en este paciente no se dan ninguno de los dos, hemos considerado pertinente comunicar a esta revista este caso, que recientemente hemos tenido la oportunidad de diagnosticar.

Varón de 85 años con antecedentes de fumador, EPOC, marcapasos VDD endocavitario por bloqueo trifasicular y síncopes de repetición, meningioma occipital parasagital izquierdo, AIT de repetición por enfermedad aterotrombótica de territorio carotídeo y vertebrobasilar, en tratamiento con dicumarínicos, fenitoina, esteroides y broncodilatadores. Presentaba además un síndrome prostático con infecciones urinarias de repetición que incluso había cursado tres meses atrás con shock séptico y era portador de sonda vesical permanente desde entonces. El paciente es llevado al servicio de urgencias del hospital, porque la mañana del ingreso comenzó con taquipnea, cianosis central y periférica, fiebre de $39^{\circ}$ y escalofríos. En la exploración física se objetiva TA: 70/40; FC: 103; $\mathrm{T}^{\mathrm{a}}$ : 38 ; Sat O2: 85\%, mal estado general, con bajo nivel de conciencia no responde a ordenes, con piel caliente y cianosis distal. C y C: pupilas mióticas y poco reactivas. No $\uparrow$ PVY. No adenopatías. No bocio. Tórax: AP: MVC. Roncus generalizados. AC: rítmico a 100 latidos/min. Abdomen: blando, depresible. No masas. No megalias. Genitourinario: puño percusión de difícil valoración. EEII: normales

Datos complementarios: bioquímica: glucosa 12 1mg/dl, creatinina $1,79 \mathrm{mg} / \mathrm{dl} \mathrm{Na}^{+} 145 \mathrm{mEq} / 1 \mathrm{~K}^{+} 4,3 \mathrm{mEq}$. Gases venosos: $\mathrm{pH}$ : $7,40 \mathrm{pO}_{2} 38 \mathrm{mmHg} \mathrm{pCO}_{2} 44,3 \mathrm{mmHg} \mathrm{HCO}_{3} 28,1 \mathrm{mmol} / \mathrm{l}$. Hgma: $\mathrm{Hb} 14,1 \mathrm{~g} / \mathrm{dl}$ Hcto $41,7 \%$ plaquetas $264.000 \mu \mathrm{L}$ leucocitos 12.700 $\mu \mathrm{L}$ (N: $95,3 \%$ L: 3,1\% M: 1,4\% Eo: $0 \%$ B: 0,2\%) coagulación: act. protrombina $16 \%$ TP 47,6 segs. TTPA 34,6 segs fibrinógeno
$461 \mathrm{mgr} / \mathrm{dl}$, orina: densidad: 1,015 , sangre $>1 \mathrm{ph}=6,0$, proteínas 70, urobilinógeno: 0,2 EU/dl, nitritos: (-), leucocitos 500 con intensa piuria.

Hemocultivo: E. coli resistente a fluorquinolonas, ácido nalidíxico, y TMP-SMX.

Urocultivo: E. coli más de 100.000 colonias con el mismo antibiograma. Se realiza una TAC abdominal (Fig. 1) en el que se objetiva cistitis enfisematosa.

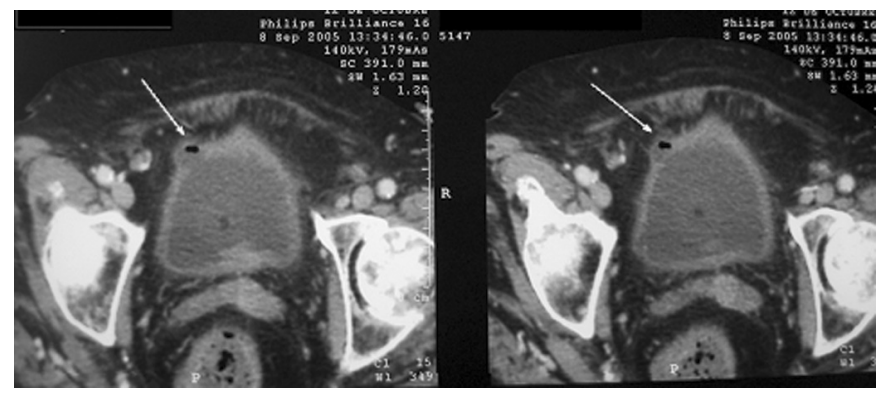

Fig. 1.

Se comenzó con amoxicilina/clavulánico, cambio de sonda vesical, soporte hemodinámico con drogas vasoactivas respondiendo adecuadamente, quedando afebril en 48 horas y recuperándose hemodinámicamente, pudiendose dar de alta a los 10 días del ingreso.

La causa de cistitis enfisematosa es la fermentación bacteriana de glucosa principalmente, muchos investigadores consideran la fermentación de la glucosa con la formación de $\mathrm{CO}_{2}$ como la mayor causa de producción de gas. El crecimiento de los organismos requiere de un constante suplemento de energía metabólica y un adecuado medio para su metabolismo. La bacteria, a través de la vía glucolítica anaerobia obtienen la energía, por la fermentación de la glucosa, obteniendo $\mathrm{ATP}, \mathrm{NAD}^{+}$que se transforman en NADH y piruvato. Para ello los microorganismos utilizan diferentes vías: a) fermentación láctica (Streptococcus, Lactobacillus); b) fermentación alcohólica (levaduras y bacterias); c) diversos ácidos (p. ej.: el ácido fórmico); y d) fermentación por enterobacteriáceas, fermentación butírica por Clostridium, fermentación butílica por enterobacteriáceas y fermentación propiónica por Propionibacterium. Algunos microorganismos como E. coli, convierten el ácido fórmico a $\mathrm{CO}_{2} \mathrm{e}_{2}$. La producción de $\mathrm{H}_{2}$ es carac- 
terística en la fermentación de varios ácidos de otra forma no se explica. El gas para formar un equilibrio con el tejido adyacente tiende a formar burbujas y estas contienen, nitrógeno, oxígeno, dióxido de carbono, hidrógeno e incluso amonio y metano por la fermentación de varios aminoácidos producidos en la degradación de la necrosis tisular. (1) Las burbujas de gas formadas por los microorganismos están sometidas a presiones y dependiendo si son presiones positivas o negativas, estas burbujas se quedan en la luz del órgano o pasan a la pared del mismo, por este juego de presiones nos podemos encontrar burbujas de gas incluso en el torrente sanguíneo. El daño tisular por el gas y la microangiopatía causan acumulación de gas. Así como el déficit inmunitario y mal control glucémico contribuyen favorablemente al proceso. Otra causa puede ser la trasformación de $\mathrm{CO}_{2}$ por la anhidrasa carbónica del hematíe y la rápida circulación por torrente sanguíneo (2).

Como agentes etiológicos encontramos principalmente bacilos aerobios gram negativos, entre ellos el más frecuente es $E$. coli al igual que en infecciones urinarias, otros microorganismos frecuentes son Klebsiella pneumoniae, Proteus mirabilis, S. aureus, Enterobacter aerogenes, Streptococcus sp. y Nocardia. Hay descrito algún caso por hongos Candida albicans y Candida tropicallis (3). También existen casos por anaerobios donde el único descrito es Clostridium perfringens (4).

La clínica que presentan estos pacientes es similar a la de una infección urinaria, disuria, polaquiuria, tenesmo vesical, nicturia, hematuria, retección urinaria. Otros casos se presentan como dolor abdominal, principalmente en hipogastrio o como hematuria macroscópica $(5,6)$. También pueden manifestarse como malestar general y sepsis fulminantes. Ya que la clínica es tan inespecífica, hay que sospechar esta entidad en pacientes que presenten los factores de riesgo anteriormente citados, como ocurre en nuestro caso, que llegamos al diagnóstico mediante la realización de pruebas de imagen, radiografía si el gas esta dentro de la luz vesical, ya que si está en la pared éste no es visible, se necesita realizar una TAC (7).

Para tratar esta entidad debemos tener un buen control de la glucemia, ya que hasta un $60 \%$ de los pacientes son diabéticos, para poder obtener una buena respuesta al tratamiento antibiótico y evitar complicaciones. El tratamiento antibiótico se administra por vía parenteral, según antibiograma. Otras medidas es la colocación de una sonda vesical, de esta manera conseguimos reposo de la vejiga, esta sonda se mantendrá hasta la resolución del cuadro. Generalmente tiene una resolución rápida, en cuatro días, por lo que el pronóstico es bueno, aunque existen casos de mortalidad, son raros (8). Una de las principales complicaciones de la cistitis enfisematosa, es la pielonefritis enfisematosa, por traslado de las burbujas de gas, otras son ruptura vesical, y sepsis $(3,5)$.

\section{TABLA I}

\section{COMO FACTORES DE RIESGO DE LA CISTITIS} ENFISEMATOSA
- Diabetes mellitus
- Sexo femenino
- Obstrucciones del tracto urinario
- Vejiga neurógena
- Fístula vésico-rectal
- Infecciones urinarias de repetición
- Colocación de sonda urinaria
- Estados de inmunosupresión

\section{Sánchez Pulgarín, P. Kessler Saiz, M. Odriozola Grijalva}

Unidad de Pluripatología de Medicina Interna. Hospital Universitario 12 de Octubre. Madrid
1. Huang JJ, Cheng KW, Ruaan MK. Mixed acid fermentation of glucose as a mechanism of emphysematous urinary tract infection. J Urol 1991 146: 148-51.

2. Wan YL, Lo SK, Bullard JM, Chang PL, Lee Ty. Predictors or autcome in emphysematous pyelonephritis. J Urol 1998: 159: 369-73.

3. Comiter C, McDonald M, Minton J, Yalla S. Fangal bezoar and bladder ruptura secondary to Candida tropicales. Urology 1996; 47: 439-42.

4. Katz D, Aksoy E, Cunha B. Clostridium perfringens emphysematous cistitis. Urology 1993; 41: 458-60.

5. Pérez B, García Hernández JA, Valdelvira NP, Torralba N, et al. Intraperitoneal bladder perforation in emphysematous cistitis. Actas Urol esp 2000; 24: 501-3.

6. Hiyosshi T, Akasu F, Fukazawa R, Takai k, Yoshitsugu M. Emphysematous cistitis and neuropathy: a report of the case with diabetes mellitus. Kansenshogaku Zasshi 2000; 75: 486-90.

7. Joseph R, Amándola M, et al. Genitourinary tract gas: imaging evaluation.Radiographics 1996; 16: 295-308.

8. Patterson J. Bacterial urinary infections in diabetes. Infec Dis Clin North Am 1997; 11: 735-50.

\section{Insuficiencia cardiaca. Diagnóstico insuficiente}

\section{Sr. Director:}

La insuficiencia cardiaca (IC) es una de las enfermedades que con mayor frecuencia se encuentra en la práctica clínica, y su prevalencia, aproximada, en España es del 5\% (18\% en mayores de 80 años). En este sentido, dicha patología resulta la primera causa de hospitalizaciones en mayores de 65 años del orden de 80.000 ingresos anuales (1). Los objetivos buscados incluyen prolongar la supervivencia y mejorar la sintomatología. Para ello no podemos conformarnos con un diagnóstico sindrómico y debemos intentar completarlo con el diagnóstico etiológico, fisiopatológico y funcional, como es el caso que a continuación exponemos.

Se trata de un varón de 70 años que acude por disnea. Como antecedente destacable mencionamos que era exfumador, desde hace 20 años. Refería cuadro clínico de unos 8 meses de evolución, de disnea y fatiga progresiva hasta hacerse de pequeños esfuerzos. En la exploración física: PA 125/75 mmHg, P 90 lpm, $\mathrm{T}^{\mathrm{a}} 36,7^{\circ} \mathrm{C}$ y FR $22 \mathrm{rpm}$, normoconstituido (IMC:23), no presentaba IVY a $45^{\circ}$. La auscultación cardiaca era rítmica a $90 \mathrm{lpm}$ con presencia de un $3^{\circ}$ tono y soplo sistólico aspirativo II/VI más audible en foco mitral que irradiaba hacia axila; y en la pulmonar se auscultaban mínimos crepitantes finos bibasales sin otros hallazgos de relevancia. Las pruebas de laboratorio mostraban un colesterol total de $276 \mathrm{mg} / \mathrm{dL}$ (N: 145-255) siendo las fracciones LDL y HDL 176 y $35 \mathrm{mg}$ respectivamente, triglicéridos 173 mg/dL (N: 35-150). El resto de los parámetros bioquímicos, hemograma, coagulación, análisis elemental de orina, hormonas tiroideas y el metabolismo del hierro no revelaban alteraciones. En la radiografía de tórax se evidenció un aumento global de la silueta cardiopericárdica y signos de redistribución vascular. En cuanto al electrocardiograma presentaba un ritmo sinusal a 88 $\mathrm{lpm}$, con bajos voltajes en derivaciones de miembros, bloqueo completo de rama derecha de haz de Hiss y alteraciones de repolarización en cara lateral con onda $\mathrm{T}$ invertida en precordiales izquierdas. Se realizó ecocardiograma transtorácico en el que se apreció dilatación del ventrículo izquierdo (VI) con severa depresión de la función sistólica (FE: 30-35\%), insuficiencia mitral ligera-moderada y esclerosis aórtica sin gradiente significativo. También se le practicó un test de esfuerzo y hubo que detener la prueba en el minuto 2 del estadio I de Bruce por fatiga. En la coronariografia se objetivó una estenosis del $95 \%$ en la descen- 